\title{
HANNAH ARENDT: PARIA Y ADVENEDIZO, DOS ACTITUDES POSIBLES FRENTE A LA JUDEIDAD ${ }^{1}$
}

Hannah Arendt: pariah and upstarts, two possible attitudes towards jewishness

Paula Calderón Melnick paulacalderonm@gmail.com Universidad de Chile

Chile

\section{Resumen}

En este trabajo analizaremos cómo se originó la asimilación judía en el contexto de la emancipación de este pueblo en la Alemania de finales del siglo XVIII y de comienzos del XIX. Para llevar a cabo este proceso explicaremos, siguiendo a Hannah Arendt, cómo surgió el concepto del pueblo judío como pueblo paria. Para luego examinar a dos modelos de judíos concretos planteados por la filósofa alemana, el judío definido como advenedizo o parvenu y su contrapartida, el paria consciente. Con este fin nos centraremos en las obras tempranas de Arendt escritas en la década de 1930, La asimilación original. Un epílogo con motivo del primer centenario de la muerte de Rahel Varnhagen; Salón Berlinés; Rahel Varnhagen. Vida de una mujer judía, además de su primera gran obra, escrita dos décadas más tarde, Los orígenes del totalitarismo.

Palabras clave: Paria - Advenedizo - Paria consciente - Asimilación judía - Judeidad.

\begin{abstract}
The following work will analyse how the jewish assimilation began in Germany, in the latest XIX Century and early XIX Century, during the jewish process of emancipation. The following pages will explain, based on Hannah Arendt, the origin of the concept of jews as pariah people. Two specific models, proposed by the german philosophy, will be examined: the parvenu and it's opposite, the conscious pariah. The focus will be in the early work of Arendt, from the 1930's decade: The original assimilation. An epilogue to the one hundredth anniversary of Rahel Varnaghen's death; The Berlin salons; Rahel Varnhagen. The life of a jewish woman, and, her first main work, The origins of totalitarianism, from 1951.
\end{abstract}

${ }^{1}$ Publicado en Cuadernos Judaicos-No 30 Diciembre 2013 
Keywords: Pariah - Upstarts - Conscious pariah - Jewish assimilation - Jewishness

\section{El pueblo judío como pueblo paria}

Al momento de examinar la historia judía en la época moderna y alguna de sus etapas más importantes, Hannah Arendt construirá su hipótesis de lectura bajo dos imágenes ideales, es decir, se centrará en dos tipos humanos que para la pensadora expresarán a dos modelos de judíos concretos: el judío definido como paria social y, su contrapartida, el advenedizo o parvenu, arquetipos que contendrán una "validez ejemplar" para la filósofa alemana (Arendt, 2003, p.141). ${ }^{2}$

En este contexto, para comprender cómo se originaron las figuras señaladas, Hannah Arendt (2010c) indicará que durante siglos los judíos estuvieron excluidos de la cultura y de la historia europea y, para los pueblos que los acogían, las masas judías quedaban relegadas a una situación de inferioridad dentro de la sociedad. Como explica la filósofa alemana, el escenario político y social para el grueso de la población judía permaneció invariable en el tiempo, en el mejor de los casos estos individuos eran tolerados, pero la regla común era que vivieran sometidos y perseguidos.

En este sentido, Arendt planteará que la reivindicación de una mejora de la realidad civil de los judíos prusianos se hará efectiva bajo la influencia de la Ilustración. Sin embargo, el grueso de la población judía quedará marginada del proceso de la asimilación a la vida europea por ser considerada que formaba parte de un pueblo paria.

Para entender lo planteado podemos recurrir a la definición del término paria, el que hace alusión a aquella persona que se encuentra excluida de las ventajas que gozan las demás, incluso de su trato, por ser considerada inferior. Y, el origen de esta palabra, hace referencia a aquel habitante de la India de ínfima condición social, que se encuentra fuera del sistema de las castas (Real Academia Española) ${ }^{2}$ Cabe destacar que Hannah Arendt también analizará en profundidad la figura arquetípica del judío de
excepción, en los textos La Ilustración y la cuestión judía y Los orígenes del totalitarismo 
Ahora bien, en la obra Antisemitismo, Arendt vinculará la noción de paria pero en relación con el pueblo judío, ligando este concepto con la ausencia de poder de este pueblo producto de su carencia de derechos políticos. En este contexto, la filósofa alemana definirá el término pueblo paria siguiendo los planteamientos de Max Weber en sus obras Historia económica en general y Sociología de la religión. Así Arendt, guiándose en los textos del pensador alemán señalará que los judíos fueron parias en tanto que no tenían poder político, lo que se relacionaba con la política de confiscación que tenían los príncipes, cuyo propósito era el de evitar que la riqueza que los judíos de excepción estaban reuniendo, se convirtiese en acumulación originaria del capital y en un primer paso hacia el capitalismo.

Como precisa la autora, el capital judío era continuamente eliminado y diseminado mediante pogroms, expulsiones y confiscaciones por parte del Estado-Nación. Por ello Weber (1964, p.302) indicará que "este era un capitalismo de parias, no un capitalismo racional como el que se produjo en Occidente".

¿Pero qué significará para los judíos ser parte de un pueblo paria en este período? ${ }^{3}$ Para aproximarnos a una respuesta podemos recurrir al ensayo de Arendt, Sobre la humanidad en tiempos de oscuridad: Reflexiones sobre Lessing. En este sentido, la filósofa alemana indicará que los pueblos parias surgirán con mayor frecuencia en los denominados "tiempos de oscuridad" (Arendt, 2008, p.23) es decir, como precisa la autora, en aquellas épocas que se tornan tan oscuras para ciertos pueblos perseguidos o grupos esclavizados, en los cuales el hecho de retirarse del mundo ya no dependerá de su propia decisión, no pasará por su elección. Y, como señala Arendt (2008), en "la Europa del siglo XVIII tenía que ser bastante natural detectarla entre los judios" (p.23), donde solo excepciones de este pueblo eran aceptadas en la vida europea en función de la marginación de las masas judías.

En este contexto, como plantea la autora, en los denominados 'tiempos de oscuridad' se originará en los pueblos parias, como el pueblo judío, lo que Lessing, referido por Arendt

\footnotetext{
${ }^{3}$ De acuerdo con la pensadora Fina Birulés, si bien Arendt (2005a) reconocerá que de Max Weber tomará el concepto de paria, la fuente del uso que hará la filósofa alemana de este término, se basará en los escritos de Bernard Lazare sobre el sionismo, autor y abogado judío francés que hizo la primera declaración pública sobre la inocencia del acusado capitán Dreyfus.
} 
(2008, p.23) denominará como "fraternidad" o "sentimientos filantrópicos", en otras palabras, aquel vínculo estrecho de hermandad e intimidad que surge entre los seres humanos a partir del trato inhumano que reciben del mundo. Sin embargo, como precisa la pensadora, producto de esta misma fraternidad que se establece entre los miembros del pueblo paria, sus integrantes, bajo la presión de la exclusión o de la persecución, se juntarán tanto entre sí, hasta tal punto, que desaparecerá entre ellos el espacio del denominado mundo, constituyéndose en cambio una condición igualitaria entre ellos sin que aparezca, de acuerdo con la autora, aquel "estar-entre específico y a menudo insustituible que debería haberse formado entre este individuo y sus semejantes" (Arendt, 2008, p.14).

De esta forma, como plantea Arendt (2008), producto de la fraternidad, en la cual desaparece el intersticio necesario entre los hombres para que se configure el mundo común, los judíos parias quedarán con "una verdadera carencia de mundo" (p.23) y correrán el riesgo de quedar con "una atrofia tan terrible de todos los órganos” (p.23), es decir, desprovistos del desarrollo necesario de cualquier parte de su cuerpo para saber cómo responder al espacio común del que son excluidos; para saber cómo comprenderlo y poder así orientarse tanto a sí mismos como a los otros, en una clara situación de bajeza en la condición social.

Sin embargo, señalará Arendt (2008), estos mismos sentimientos filantrópicos entre los miembros de este pueblo insultado y lastimado serán "su gran privilegio" (p.23) ya que harán que entre los miembros de este pueblo se produzca "una calidez en las relaciones humanas que para aquellos que tuvieron alguna experiencia con estos grupos puede parecer casi un fenómeno físico" (p.23). Y, de acuerdo con la autora, cuando esta misma calidez, como sustituto de la luz del espacio público, se encuentra en su pleno desarrollo, surgirá de ella, a su vez, entre los integrantes de esta comunidad perseguida y excluida, la "humanidad, amabilidad, ausencia de prejuicios (y) sensibilidad antes la injusticia" (Arendt, 2010a, p.141). Y, junto con estas cualidades, aparecerá "una vitalidad y una alegría por el simple hecho de estar vivos" (Arendt, 2008, p.23).

De acuerdo con Arendt (2008, p.23), estas características y el "encanto y la intensidad de la 
atmósfera que se desarrolla" en los judíos parias, se deberá a que este pueblo disfrutará del "gran privilegio de no soportar la carga de cuidar del mundo" (p.23). Ello quiere decir, siguiendo a la pensadora, que este tipo de judíos al estar marginados de las ventajas y privilegios proporcionadas por el Estado o la sociedad prusiana, es decir, al estar excluidos de la esfera pública, quedarán a su vez imposibilitados de sobrellevar 'la carga del mundo', ya que sencillamente no podrán ingresar en él, no podrán aparecer en el ámbito común. Y, al no poder participar de esta esfera, a este tipo de judíos no se les impondrá la responsabilidad para con el mundo y la vida pública.

Para comprender lo señalado, Arendt (2008) planteará que si reflexionamos acerca de la apertura hacia los demás, como una de las condiciones previas de la humanidad en todos los sentidos que pueda tener esta palabra, el compartir la alegría será superior en este aspecto que compartir el sufrimiento. De acuerdo con la pensadora, la alegría y no la tristeza será lo elocuente, es decir, la facultad que producirá el hablar o el escribir de modo eficaz para deleitar, conmover o persuadir a los demás con viveza. Y, como precisa Arendt, el verdadero diálogo entre los hombres se diferenciará de la charla o incluso de la discusión, en que el diálogo estará impregnado por el placer que causa el estar con la otra persona y lo que ella dice, por lo cual el diálogo estaría afinado en la clave de la alegría.

Y, de acuerdo con la filósofa alemana, será precisamente este diálogo, pero trasformado en una completa intimidad y cercanía con el otro, sin espacios entre sí, el que se originará del placer, de la alegría y de la vitalidad que surge del estar los unos junto con los otros, lo que potenciarán los judíos parias para contrarrestar su sufrimiento y su carencia de mundo (Arendt, 2008).

Siguiendo a Arendt (2008), los judíos parias vivirán así en un espacio confinado, donde las personas se reunirán para darse calor las unas a las otras, en una excesiva fraternidad que borrará toda diferenciación. Y este tipo de relación que se establecerá, como señala la pensadora, compensará la extraña irrealidad que las relaciones humanas adquieren cuando se desarrollan en la falta del ámbito común, cuando las relaciones se establecen sin estar vinculadas al mundo que comparten todas las personas. 
Como señala Ron H. Feldman en la Introducción al libro Hannah Arendt. Escritos judíos, el estatus del paria será entonces el del marginado social y es la posición que caracterizará a los judíos a partir de la Ilustración y de la emancipación judía, ya que los miembros de este pueblo no fueron realmente aceptados en la sociedad alemana. En este sentido, de acuerdo con Feldman, Arendt se centrará en el problema de la judeidad en los judíos parias en el mundo moderno, es decir, en la transformación de su judaísmo, considerado por el autor, siguiendo a la filósofa alemana, como un sistema de creencias que los judíos pueden aceptar o rechazar; el que se trasformará en judeidad, en una condición existencial dada de la que no se puede escapar. (Kohn \& Feldman editores, 2009)

¿Pero qué quiere decir aquello? Para profundizar en este análisis, podemos recurrir a la definición de estos términos, efectuada por el traductor del libro anteriormente indicado:

Traduzco el vocablo 'Jewishness' como 'judaicidad' (judeidad) o, también en algunos casos, como 'condición judía', a fin de distinguirlo de 'Judaism', que traduzco como 'judaísmo'. La razón de hacerlo así es que existe una notable diferencia entre ambos términos. El primero de ellos (Jewishness) señala el simple hecho de 'ser judio', como condición existencial del individuo, un factum que condiciona su existencia y que, como tal, no puede ser negado, si bien constituye una 'dotación meramente pasiva del ser'(del individuo). El segundo (Judaism) hace referencia a la religión, la tradición y la cultura judía, es decir, a las creencias, la historia y las costumbres de los judios en cuanto pueblo. (Kohn \& Feldman editores, 2009, p.16)

En este sentido, para comprender el concepto de judeidad expresado por Arendt (2010a), nos podemos basar en los planteamientos de Fina Birulés en la Introducción al libro Hannah Arendt. Una revisión de la historia judía y otros ensayos. La filósofa española indicará que cuando Arendt (2005a) se refiere a la judeidad como el simple hecho de 'ser judío', como una 'dotación meramente pasiva del ser' o como un "dato incontrovertible" (p.13), estará señalando todo aquello que no se ha elegido, donde no ha intervenido la iniciativa. Es decir, como explica Arendt en su Carta a Gershom Scholem, todo aquello que 
"es dado y no hemos hecho, ni puede ser hecho" (Kohn \& Feldman editores, 2009, p.570).

Birulés explicará que nadie escoge nacer hombre o mujer, judía o no judía. Como señala la pensadora española, todo individuo al nacer recibe algo de contingente y no elegido, algo que 'es dado y no hemos hecho, ni puede ser hecho'. De esta forma, Birulés dirá que cuando Arendt (2005a) reflexiona sobre la judeidad como lo que 'es dado', no lo realizará para indicar un tipo específico de personas, sino que se referirá a un "presente político" (p.13), a una cierta configuración del mundo que no tiene relación con una determinación natural o biológica, ya que toda vida, indica la pensadora española, surge en un momento concreto y en un tiempo específico, en el entorno de una comunidad y con unas características físicas o psicológicas particulares.

Sin embargo, la filósofa española explicará que para Arendt el pensar y actuar a partir de la condición judía, de la judeidad, no se traducirá en que aquello configure una visión del mundo. Birulés indicará que para Arendt (2005a, p.13) lo que caracterizará a las personas será su capacidad de juzgar "y el primer mandato, al que siempre se mantendrá fiel, es el de 'pensar por sí misma' (Selbstdenken de Lessing)".

Ello implicará, siguiendo a Birulés, que ejercemos el juicio sobre el fondo de un contexto concreto, de una coyuntura específica, por ello "pensar por sí mismo no es pensar a partir de nada, sino tomar posición, responder de y a lo que nos ha sido dado" (Arendt, 2005a, p.13). De esta forma, la pensadora española explicará que lo que nos ha sido otorgado no determinará nuestra visión del mundo y, por ello, frente a lo dado, se tomará una posición.

Para ahondar en los conceptos de judaísmo y judeidad, Martine Leibovici (2005) señalará en su texto Hannah Arendt y la tradición judía. El judaísmo a prueba de la secularización, que para Arendt el judaísmo se remitirá a "a la ortodoxia (...) y al pueblo judio que hablaba yiddish ${ }^{4}$ y que producía un folclore" (p.8). Sin embargo, indicará Leibovici, cuando Karl Jaspers le hace notar a Arendt que ser judío quería decir para él "la religión bíblica, la idea de Dios y la idea de la Alianza" (p.8); la filósofa alemana, referida por Leibovici, le

\footnotetext{
${ }^{4}$ Dialecto de los judíos askenazíes, es decir, judíos alemanes y polacos.
} 
responderá: "Desde el punto de vista histórico, sin duda usted tiene razón. Pero el hecho es que muchos de los judíos son como yo, totalmente independientes del judaísmo, y son, sin embargo, judios" (p.8).

De esta respuesta de Arendt se infiere, como plantea Leibovici, que la preocupación de la pensadora se centrará en la judeidad, en aquello que 'es dado y no hemos hecho, ni puede ser hecho', en aquellos judíos que siendo independientes de su judaísmo, siguen siendo judíos o en la experiencia judía vivida en el contexto alemán durante la emancipación de este pueblo; más que centrarse en el judaísmo propiamente tal, en las tradiciones judías, en las fuentes judías de pensamiento o en los individuos que activan en la comunidad judía.

Entonces, será en este contexto en el que la filósofa alemana examinará a los judíos parias, es decir, analizará a aquellos individuos de este grupo que se intentan asimilar a la vida europea para dejar de lado su situación de marginalidad. En este sentido, Feldman indicará que los judíos parias al tratar de insertarse a la sociedad alemana, habían perdido la herencia judaica de sus padres, pero sin haber obtenido como reemplazo un lugar bien asentado en la realidad política prusiana. Por ello, en este tipo de individuos su judaísmo se trasformará en judeidad al intentar tener una experiencia como europeos y como seres humanos en general en la modernidad, pero sin tener una base judaica sólida a la cuál poder aferrarse. (Kohn \& Feldman editores, 2009)

De esta forma, podemos plantear que existirán diversas formas para responder a la judeidad. Arendt planteará que el estatus marginal del pueblo judío como pueblo paria, dará lugar a dos tipos particulares de judíos, quienes en su intento por insertarse a la vida europea responderán a su condición judía en la forma de parias conscientes o como su contrapartida los advenedizos o parvenu.

Ahora bien, antes de ingresar en la definición de los dos arquetipos planteados, debemos mencionar que tanto el paria como el advenedizo no representarán tan solo dos respuestas posibles frente a la tensión existente entre judaísmo y judeidad. Además, estas dos figuras corresponderán a dos formas defectuosas para resolver el conflicto que los judíos como 
miembros de un pueblo paria tenían con la sociedad receptora, problema que parecía no tener solución.

En este sentido, Fina Birulés subrayará que Arendt (2005a) al referirse al proceso de emancipación de los judíos en Europa desde fines del siglo XVIII, destacará el compromiso que surge alrededor del concepto de la igualdad desde la Ilustración. Sin embargo, la pensadora precisará, siguiendo a Arendt, que en este período el concepto de igualdad se confundirá con la idea de la uniformidad; confusión que se verá ampliada por las reivindicaciones características de los modernos Estados-Nación, en función de una existencia homogénea y autónoma. Por ello, como señala Birulés, la filósofa alemana a pesar de conceder una importancia fundamental al hecho de que los judíos debían pertenecer a un Estado, también será consciente de que los derechos de ciudadanía que se establecían en el Estado-Nación podían llegar a ser limitadores de la diversidad humana.

De acuerdo con Arendt (2010a), la vida política descansará en la presunción de que podemos producir la igualdad "como resultado de la organización humana, en tanto que resulta guiada por el principio de la justicia" (p.425), del actuar del hombre en un mundo común, el cual puede cambiarse y construirse junto a los otros. En este sentido, como explica Birulés, para la filósofa alemana el concepto de igualdad estará contenido en el derecho de toda persona a formar parte de una comunidad política, a formar parte del espacio público, el derecho a que todo individuo pueda ser ciudadano de algún Estado. Y ello cobrará especial relevancia dadas las condiciones en las que vivía el pueblo judío en el siglo XVIII y a principios del XIX, donde estos individuos eran considerados como parte de un pueblo paria al estar enfrentados al problema de la cuestión judía, es decir, a la situación problemática de ser un pueblo específico que vivía en una tierra que no era la suya, sino que la de otro pueblo, viviendo por ello sin estatus civil o jurídico por parte del Estado y la sociedad mayoritaria que los acogía. En otras palabras, se trataba de una comunidad que se caracterizaba por su carencia de mundo, de un lugar físico en el que las personas pudiesen tener sus raíces y desde el cual pudiesen orientarse en el mundo, aprehender la realidad y la historia. (Kohn \& Feldman editores, 2009) 
En este sentido, Arendt (2005b) indicará en la Conversación con Günter Gaus, que el pueblo judío no fue siempre un pueblo apolítico, ya que de acuerdo con la autora, "las comunidades (judías) también eran hasta cierto grado políticas" (p.34), incluso, dirá la pensadora, no se puede perder de vista que "la religión judía es una religión nacional" (p.34). Pero, como dirá la filósofa alemana, el concepto de lo político solo regirá en ella con ciertas restricciones, ya que el pueblo judío sufrió la pérdida del mundo con la dispersión y con su trasformación en un pueblo paria.

En este contexto Leibovici (2005) planteará que Arendt sin haber profundizado sistemáticamente en esta materia, considerará que la tradición judía, al igual que la tradición griega o la romana legó conceptos políticos a la tradición occidental a partir de su religión, los que la autora ejemplificará en los conceptos de la liberación de la esclavitud y de la noción de la Ley basada en la Alianza. Sin embargo, Leibovici dirá que el acosmismo del pueblo judío es más el efecto de su condición de paria en la historia europea que un rasgo distintivo de su religión.

Ahora bien, otro factor a considerar al momento de analizar al pueblo judío como pueblo paria será el que el individuo judío al momento de intentar insertarse a la sociedad alemana, como indica Birulés, se obstinó en no observar la discriminación social y el antisemitismo que sufría, ya que creyó que el mundo se le abriría en tanto fuese como los demás miembros de la sociedad prusiana, en cuanto fuese igual o uniforme a los demás, es decir, en tanto desapareciese como judío (Arendt, 2005a).

De esta forma, como señala Birulés, la condición judía colectiva se vio progresivamente no percibida, transformándose la inserción colectiva del pueblo judío a la sociedad alemana, en un problema para cada individuo judío que tensionaba su propia vida privada. Con tal que, como indica la autora, los judíos ingresaron de uno en uno en las distintas comunidades nacionales, y no como un grupo social y político cohesionado que demandase su espacio en la esfera pública en función de la diferenciación de su condición judía. ${ }^{5}$

\footnotetext{
${ }^{5}$ En este contexto para Arendt (2005a), frente a la falta de realidad y carencia de mundo del judío paria, el sionismo representó para la autora durante un cierto período, hasta antes de 1950, una reacción positiva de los judíos frente a la opresión de la sociedad.
} 
Para entender las implicancias de esta falta de poder político en el proceso de asimilación de los judíos parias a la sociedad alemana, podemos recurrir a la obra madura de Arendt, $L a$ condición humana, escrito décadas más tarde en relación a sus textos sobre la emancipación judía en el siglo XVIII. En este sentido, la pensadora planteará que:

Es el poder lo que mantiene la existencia de la esfera pública, el potencial espacio de aparición entre los hombres que actúan y hablan (...) el poder es siempre un poder potencial (...) surge entre los hombres cuando actúan juntos y desaparece al momento en que se dispersan. (Arendt, 2010b, p.223)

De esta forma, siguiendo a la pensadora, el poder al ser una potencialidad, puede realizarse pero nunca materializarse plenamente y será independiente de los elementos materiales, ya sea del número o los medios. No obstante lo anterior, precisará Arendt (2010b), el único factor material indispensable para la generación del poder será "el vivir unido del pueblo" (p.224). Ello quiere decir, como indica la autora, que solo donde los seres humanos viven unidos y donde las potencialidades de la acción siempre están presentes, el poder puede permanecer con ellos, ya que el "poder surge entre los hombres cuando actúan juntos" (p.224), en una pluralidad irreductible, lo que implica a su vez, el espacio público de la aparición, donde somos iguales pero diferentes a la vez.

Así, como precisa la pensadora, será el poder lo que mantendrá unido al pueblo luego de que haya pasado

Así, como precisa la pensadora, será el poder lo que mantendrá unido al pueblo luego de que haya pasad

el momento fugaz de la acción y lo que al mismo tiempo el pueblo mantiene vivo al estar unido. Sin embargo, la única limitación del poder será la existencia de otras personas, pero de acuerdo con Arendt (2010b, p.224), esta limitación no es accidental, ya que "el poder humano corresponde a la condición de la pluralidad para comenzar". 
Para complementar lo señalado podemos recurrir a las palabras que pronunciará Arendt (2005b, p.34) en la Conversación con Günter Gaus en 1964:

Pertenecer a un grupo es antes que nada una condición natural. Se pertenece a uno u otro grupo por nacimiento, siempre. Pero pertenecer a un grupo (...) en un segundo sentido, es decir, formando un grupo organizado es cosa enteramente distinta. Esta organización se produce siempre en relación con el mundo.

De esta cita se desprende, como precisa Birulés siguiendo a Arendt (2005a), que la noción de pueblo estará relaciona al mismo tiempo con aquello que 'nos es otorgado' y, por otra parte, con el fruto de organizarse a partir de intereses comunes; y, será esta segunda definición, la que estará relacionada con el poder político. En este sentido, Arendt (2005b) explicará que la organización de un grupo que se relaciona con el mundo como espacio donde surge la política, como el lugar donde las cosas se vuelven públicas, el espacio en que se habita, el lugar donde todo lo posible aparece, implicará que los individuos que se organicen en esta comunidad tengan en común "lo que habitualmente llamamos intereses" (p.34), en función de participar del poder político.

De esta manera podemos decir, siguiendo los planteamientos de Arendt en su obra $\mathrm{La}$ condición humana y en la Conversación con Günter Gaus, publicadas décadas más tarde en relación a sus textos sobre la emancipación judía; cómo los miembros del pueblo judío de principios del siglo XIX al intentar ingresar cada uno de forma separada a la sociedad europea, perderán la oportunidad de aparecer en la esfera pública como un grupo organizado en relación con el 
mundo, que demande su espacio en el ámbito público; perdiendo así la oportunidad de ver la condición judía desde lo público y los político, desde el punto de vista judío sobre el mundo, interviniendo en la esfera pública para representarse como comunidad, para ponerse en juego, tomando determinaciones del propio destino, desde la acción común coordinada por medio del lenguaje.

Asimismo, este grupo de judíos perderá la posibilidad de organizarse a partir de intereses comunes en función de participar del poder, es decir, de constituirse a partir del vivir unidos en cuanto pueblo, para aparecer y existir en diversidad entre los seres humanos que actúan y hablan en igualdad y distinción. Ya que solo donde los hombres viven unidos y donde la potencialidad de la acción y del discurso está presente, surge el poder que puede permanecer junto con ellos. De esta manera, estos individuos al no actuar desde el poder, quedarán aislados, sin aparecer en el ámbito común y quedando por ello impotentes del actuar político. (Arendt, 2005a)

De esta forma, para estos judíos que se intentaban insertar a la vida europea, su proceso de asimilación no estará relacionado a la significación política, sin embargo, como precisa Arendt (2010a), contaminaba sus vidas privadas e influía en sus decisiones personales. Así, los judíos, como plantea la autora, intentarán resolver su inserción a la sociedad prusiana por medio de su experiencia íntima y de sus emociones particulares, en vez de enfrentarlo como un problema político. Con tal que, como señala la filósofa alemana, los irresueltos problemas de significación pública, invadirán la vida privada de los judíos; vida privada que de acuerdo con Arendt, estará mejor gobernada por la pasión que por las consideraciones políticas.

\section{El advenedizo judío}


Como señala Arendt en al artículo Paciencia activa:

Para los individuos existía (...) un camino para salir de esta existencia de paria:

podían convertirse en advenedizos. El advenedizo social es un fenómeno típico del siglo

XIX (...) Dependía de él si quería cambiar (la figura del paria) (...) por la miseria y la estupidez de alguien que debe renunciar expresamente a toda naturalidad, a toda solidaridad humana y a toda aproximación no sesgada a las relaciones humanas. (Kohn \& Feldman editores, 2009, p.215)

De esta cita se desprende que los judíos como miembros de un pueblo paria tendrán una opción para salir de su existencia como marginados sociales, y esta elección consistirá en transformarse en advenedizos o parvenu, alternativa que cada judío deberá enfrentar de forma individual. En este sentido, como indica Birulés, siguiendo los planteamientos de Arendt, el advenedizo será aquel individuo judío que, enfrentado a su judeidad, tendrá la actitud de negar lo que le ha sido dado, de rechazar "las fibras que lo constituyen con el fin de ser reconocido y poder asimilarse" (Arendt, 2005a, p.15).

Ello quiere decir, de acuerdo con la pensadora española, que el parvenu será aquel sujeto que con tal de insertarse y ser aceptado por la sociedad europea, tendrá la actitud de oponerse al don recibido, al presente de la judeidad o de cualquier otra diferencia, sin 
querer tomarlos como propios. Se tratará de aquella persona, como precisa Birulés, que no tomará la iniciativa en relación a su condición judía, no intentará representarlo ni ponerlo en juego a través de la palabra o de la acción en un escenario donde se encuentra con los otros. (Arendt, 2005a)

Para comprender en qué consistirá el arquetipo del parvenu podemos recurrir al "caso ejemplar" (Kohn \& Feldman editores, 2009, p.100) de Rahel Lewin ${ }^{5}$ y a la asimilación original que vivirá al intentar insertarse a la sociedad alemana. En este sentido, Fina Birulés (F. Birulés, entrevista personal, 13 de noviembre de 2012) señalará que a menudo sabemos de la judeidad por la actitud que asumen ciertos individuos frente a ella, y Arendt parece preguntarse por 'lo dado' judío, a través de cómo una mujer tan singular como Rahel lo pondrá en juego.

${ }^{5}$ Conocida también como Mademoiselle Lévi, 'la pequeña Levi' y, más tarde, como Rahel Varnhagen. Arendt analizará en profundidad el salón berlinés de Rahel Varnhagen en los textos La asimilación original. Un epílogo con motivo del primer centenario de la muerte de Rahel Varnhagen; Salón Berlinés; Rahel Varnhagen. Vida de una mujer judía y en Los orígenes del totalitarismo. 
Como explica Arendt (2010a), Rahel Lewin dirigirá el más representativo de los salones berlineses judíos de su época, en el que se reunía la sociedad más mezclada de toda Alemania, en el que hubo la mayor igualdad entre los distintos. Sin embargo, como precisa la pensadora, cuando 'la pequeña Levi' pierde su salón berlinés, enfrentada a su existencia como miembro de un pueblo paria, frente a su estatus de marginada social y a sus deseos de insertarse a la vida europea decidirá, en una primera instancia, enfrentada con su judaísmo y su judeidad, tomar el camino de la advenediza.

En este sentido si analizamos la raíz de la palabra advenedizo podemos observar cómo hace referencia a aquel gentil o mahometano convertido al cristianismo (Real Academia Española). Dada esta definición, podemos apreciar que Rahel se transformará en parvenu al convertirse al cristianismo y cambiar su nombre por el de Friederike Robert.

Como explica la filósofa alemana, Rahel como advenediza tendrá una verdadera conversión interna. Rahel quiere dejar de ser ella misma, quiere renunciar a su judeidad, borrando cualquier huella que la identifique como judía. Se tratará de una decisión, como plantea Arendt (2010c, p.33), en la cual Rahel estará diciendo "no a nosotros mismos", no a la pertenencia a su condición judía, intentando borrar las fibras que la constituyen, las cualidades específicas que la diferencian de los demás, abandonando su propia originalidad y la independencia de pensamiento que la caracterizaba.

Ahora bien, cabe destacar que el origen de la palabra advenedizo también se relacionará con aquel extranjero o forastero, que no es natural u originario del lugar en el que vive y que, siendo de origen humilde y habiendo reunido cierta fortuna, pretende figurar entre gentes de más alta condición social (Real Academia Española). Siguiendo esta definición, Arendt planteará una nueva conceptualización de la figura del parvenu la que se vinculará con aquellos individuos judíos de principios del siglo XIX quienes vivían en "la locura especulativa de alguien que pierde todas las conexiones naturales, que vive solamente para sí mismo en un mundo irreal de transacciones financieras" (Kohn \& Feldman editores, 
2009, p.215). 
En este sentido, estos advenedizos judíos a los que hará alusión la filósofa alemana, se caracterizarán por ser considerados como extranjeros por la sociedad prusiana, e intentarán salir de su situación de marginalidad frente al Estado-Nación en base a su éxito económico, pero sin desear por ello abandonar su comunidad judía de origen. Como precisa Arendt (2010a, p.141), se tratará de los “judios del mundo de los negocios”, quienes de acuerdo con la autora, tenían que tener "las cualidades que el 'advenedizo' debía poseer si querían triunfar -inhumanidad, avaricia, insolencia, rastrero servilismo y determinación para medrar-" (p.141).

Como señala la pensadora en el ensayo Nosotros los refugiados, este tipo de advenedizos del 'mundo de los negocios', “empezó con los judíos cortesanos y siguió con los judíos millonarios y filántropos" (Kohn \& Feldman editores, 2009, p.364). Y, justamente, a este tipo específico de individuos, la filósofa alemana les atribuirá "todos los defectos judíos -la falta de tacto, la estulticia política, los complejos de inferioridad y la mezquindad con el dinero-" (p.364). Para Arendt, estos judíos tendrán las características mencionadas ya que ellos no creían que valiera la pena cambiar sus atributos y su enfoque de la realidad, su "estrechez del espíritu (...) la irrealidad esencial de las transacciones financieras" (p.364), en función de perseguir sus propios intereses e intentar triunfar económicamente en el mundo gentil.

En la columna Todo Israel cuida a Israel, Arendt contextualizará el escenario en el que surgirán este tipo de advenedizos judíos del 'mundo de los negocios'. La pensadora explicará que en el período previo a la emancipación cuando los judíos todavía vivían en una comunidad autónoma, en el ghetto, de acuerdo con la autora, toda la congregación se encargaba de pagar al príncipe los impuestos y las deudas de cada uno de sus miembros individuales, el "ghetto era una gran compañía mutua de seguros" (Kohn \& Feldman editores, 2009, p.231). Sin embargo, la filósofa alemana indicará que durante los siglos XVII y XVIII, los judíos de la corte asumirán esta tarea, ya que de acuerdo con Arendt, su poder sobre la comunidad judía se basará en su riqueza y en su relación con los príncipes; y, su posición en la corte, se sostendrá en la utilidad económica prestada y en las 
conexiones financieras que derivarán de este hecho. 
En este sentido, Arendt precisará que en este período surgirá "el régimen plutocrático de una clase doblemente poderosa de advenedizos" (Kohn \& Feldman editores, 2009, p.231). Ello quiere decir, siguiendo a la filósofa alemana, que los advenedizos del 'mundo de los negocios' asumieron la responsabilidad por aquellos a los que debían su riqueza y poder, el Estado o el príncipe. Y, a su vez, como indica Arendt, la comunidad judía se dejó gobernar por los judíos advenedizos, ya que a ellos debían su seguridad y sus posibilidades de entrar en la sociedad prusiana. En este contexto, Ron Feldman caracterizará a este tipo de advenedizos judíos como individuos arribistas que tratan de progresar en la sociedad no judía. Para Feldman se tratará de sujetos que:

Trepan en el mundo 'respetable' de los gentiles pisoteando a los demás judios. En el

mejor de los casos, se acepta a los advenedizos como 'excepciones' al estereotipo del

judío ingenuo y desdeñado del ghetto, y aquellos judíos que tienen éxito con dicho truco se sienten superiores a los demás judíos. (Kohn \& Feldman editores, 2009, p.45)

Finalmente, Arendt (2010c) también relacionará la noción de advenedizo con individuos no judíos, específicamente con aquellos sujetos que tendrán un fuerte anhelo por ascender y ser reconocidos socialmente. En este sentido para la pensadora, August Varnhagen, el esposo de Rahel Lewin, será considerado como el advenedizo por excelencia.

\section{Paria consciente}


Ahora bien, como indica Arendt, durante el siglo XIX existió una minoría de judíos que, enfrentados a su condición judía y al proceso de asimilación a la vida europea, no quisieron convertirse en advenedizos o parvenu, frente a su existencia como miembros de un pueblo paria. A este tipo de judíos la pensadora los denominará parias conscientes.

La filósofa alemana indicará en el texto La tradición oculta, que el paria consciente: 
Viviendo en los países de la emancipación, en vez de ceder a la tentación del

mimetismo estúpido de la carrera del parvenu, intentaron tomarse el gozoso mensaje de

la emancipación más en serio de lo que nadie había pretendido nunca y ser -en su

condición de judios-seres humanos (...) los judios, a los que se les negaba la libertad

política y el contacto directo con la población, se liberan a sí mismos como seres

humanos y como individuos particulares. (Kohn \& Feldman editores, 2009, p.366)

De esta cita se desprende que los parias conscientes se caracterizarán por querer emanciparse e integrarse a la sociedad alemana, pero como seres humanos individuales desde su propia condición de judíos. Ello quiere decir, como señala Birulés, siguiendo los planteamientos de Arendt (2005a, p.14) que estos sujetos enfrentados con su judaísmo y su judeidad, sentirán "gratitud por el don recibido, por el presente de la judeidad o de cualquier otra diferencia", con tal de tomar las cualidades que los caracterizan como propias y tener la iniciativa en relación a lo que les ha sido otorgado.

De esta forma, de acuerdo con Birulés, los parias conscientes tendrán el empuje y el coraje para representar su condición judía u otra diferencia que los caracterice a través del discurso y la acción, en la realidad del mundo común donde se encuentran los unos con los otros. Como precisa la pensadora española, estos individuos tendrán así el gesto de aceptar lo dado y comenzar desde ahí, lo que permite que aparezca en ellos una subjetividad singular, ya que como indica la autora, esto supone que cada individuo tome alguna 
iniciativa en relación al don que ha recibido. (Arendt, 2005a)

Así, como plantea Birulés, "cada persona puede entenderse como una variación -y no como una cancelación- siempre única de las diferencias que tiene en común con otros" (Arendt, 2005a, p.15). Ello quiere decir, de acuerdo con la autora, que más que interesar cuál es el efecto de haber nacido como judío, lo que importará será cómo ciertos judíos viven su vida en la escena del mundo en igualdad y distinción. Por ello, dirá la pensadora española, que Arendt no considerará 
que una biografía individual esté determinada por lo dado, sino que por las distintas formas en cada sujeto responde a ello.

Oponiéndose apasionadamente a su entorno tanto judío como no judio, (los parias

conscientes) se acercarán por propia iniciativa, con la imaginación de la cabeza y el

corazón, al pueblo. La exaltación de la pasión y la imaginación que exigía esta meta

constituyó el auténtico caldo de cautivo de la genialidad judía. (Kohn \& Feldman

editores, 2009, p.366)

Para comprender la referencia indicada por Arendt, podemos recurrir a los planteamientos de Ron Feldman. Como señala el pensador, siguiendo a la filósofa alemana, los parias conscientes serán aquellos individuos que saben cuál es su estatus, es decir, que piensan, quieren y obran en relación al conocimiento que tienen de la realidad de su condición de judíos parias. Y, justamente, dirá el autor, al afirmar al mismo tiempo su judeidad y su derecho a un sitio en la sociedad alemana, estos individuos se trasformarán en sujetos marginales no solo para la vida europea, como el resto de los judíos parias, sino que también en relación a su propia comunidad de origen. (Kohn \& Feldman editores, 2009)

Como precisa la pensadora, los parias conscientes a través de su libertad de consciencia, del 
"pensamiento autónomo" referido por Lessing (Arendt, 2010c, p.28) o del "pensar sin barandillas" señalado años más tarde por Arendt (1995, p.139); a través de la liberación de sí mismos como seres humanos particulares, lograrán vincular su judeidad con su pueblo de origen, y ello lo realizarán no a través de la religión, las creencias, las costumbres o las tradiciones judías; sino que a través de la cultura, la imaginación y la creatividad.

Para entender esta vinculación del paria consciente con su condición judía a través de la cultura, podemos recurrir a los planteamientos de Arendt (2005a) en el texto La creación de una 
atmósfera cultural, donde la autora explicará cómo se desarrolló el proceso de secularización para los judíos durante la emancipación de este pueblo en los siglos XVIII y XIX.

En este sentido, como señala la filósofa alemana, la cultura como se la entiende en la actualidad, surge de la secularización de la religión y de la disolución de los valores tradicionales desde el Renacimiento en Europa occidental; donde la secularización, de acuerdo con la pensadora, trasformó los conceptos religiosos y los resultados de la especulación religiosa, de tal forma, que recibieron un nuevo significado y una nueva relevancia independiente de la religión.

Como explica Arendt (2005a, p.17), esta trasformación marcó el comienzo de la cultura como la conocemos hoy, es decir, "a partir de entonces la religión se convirtió en una parte importante de la cultura, pero dejó de tener el dominio sobre todos los logros del espíritu". Y, precisamente, porque las viejas tradiciones religiosas ya no estaban presentes en este período, se impulsó el nacimiento de la cultura.

En este contexto, Leibovici (2005), siguiendo los planteamientos de la filósofa alemana, indicará que los contenidos de la religión se volverán contenidos de la cultura y adquirirán así una nueva significación independiente de la fe. De esta forma, explicará Leibovici, la cultura se transformará en una nueva forma de vincularse con el pasado y de garantizar un lazo entre las nuevas generaciones con las más antiguas, reemplazando así la cultura a las tradiciones y a la autoridad religiosa.

Si analizamos la secularización del pueblo judío, Arendt (2005a) explicará que este grupo no solo no participó en el lento proceso de secularización que comenzó en Europa occidental con el Renacimiento y del cual, de acuerdo con la filósofa alemana, nació la cultura. Sino que, como señala la autora, los judíos entrarán en contacto con la secularización y la cultura occidental principalmente durante la Ilustración, cuando este 
proceso estaba considerablemente avanzado.

En este contexto, como plantea Leibovici (2005), la emancipación de los judíos en este período estuvo acompañada por una crisis de la autoridad en el interior de las comunidades judías. Como 
precisa la filósofa francesa, cuando en la época previa a la emancipación, los judíos de la corte iniciaron su ascenso social y el Estado comenzó a intervenir cada vez más en la vida de las comunidades judías con el objetivo de limitar la competencia de sus jurisdicciones autónomas heredadas de la Edad Media, la autoridad de los rabinos sufrió una fuerte desestabilización. De acuerdo con la pensadora, ello produjo que la observancia de los ritos judíos se relajase en los medios judíos acomodados y se estudiase cada vez menos la Torá y cada vez más las materias profanas, actitud que se generalizó tras la emancipación judía.

En este contexto, como explica Leibovici (2005, p.80), en sí mismos estos comportamientos no tenían nada de nuevo "ya que las comunidades judías siempre tuvieron que ver con transgresiones". Sin embargo, dirá la pensadora, la tradición judía podía combatir las trasgresiones en el ghetto, incluso denominarlas como herejías y, la mayor parte del tiempo, el acusado aceptaba las reprimendas y ello podía incluso reforzar la autoridad del rabino en la comunidad. No obstante lo anterior, como plantea la autora, a fines del siglo XVIII ello ya no será posible, ya que los individuos que se apartaban de las normas judías tradicionales al intentar insertarse en la vida europea, se apoyarán en otro sistema de valores, por lo general en el racionalismo de la Ilustración, y ya no en los juicios emitidos por los rabinos.

Como explica Leibovici (2005) los rabinos al principio fueron tomados por sorpresa, no alcanzaban a dar sentido a este fenómeno y desarrollaron nuevas estrategias de adaptación en la que su preocupación por mantener la tradición debía arreglárselas con la transformación de las individualidades. Pero como precisa la pensadora el entusiasmo por la Ilustración que atrajo a los judíos a intentar asimilarse a la sociedad europea hizo que muchos de ellos escapasen finalmente de la autoridad de los rabinos y abandonasen por completo el judaísmo.

De acuerdo con Arendt (2005a, p.18) estos individuos judíos al alejarse de su judaísmo quedarán carentes de los: 
Vínculos espirituales entre la civilización judía y la no judía (...) los judios que querían 'cultura' dejaron el judaísmo de una vez por todas, aunque la mayoría de ellos mantuvieran la consciencia de su origen judío. (En) La secularización, e incluso el

aprendizaje secular, (los judíos) se identificaron exclusivamente con la cultura no judía, de modo que nunca se les ocurrió a esos judios que podrían haber puesto en marcha un proceso de secularización con respecto a su propia herencia. Su abandono del judaísmo llevó a una situación dentro del propio judaísmo en que la herencia espiritual judía

pasó a ser más que nunca monopolio de los rabinos.

En este sentido, como indica Leibovici (2005) desde entonces se observó un distanciamiento cada vez mayor entre los rabinos, dedicados a conservar la tradición judía, y los intelectuales judíos que producían sus obras en una diversidad de campos culturales cada vez más importantes y en el idioma de los Estado-Nación en los que poco a poco se volvían ciudadanos.

Sin embargo, dirá Arendt (2005a), que aunque esta drástica huida de la autoridad y la tradición religiosa judía por parte de los intelectuales judíos "impedía el crecimiento de una atmósfera cultural en la comunidad judía, fue muy favorable para el desarrollo de la creatividad individual" (p.19). Ello quiere decir, de acuerdo con la pensadora, que mientras 
que lo que otros individuos de otras naciones habían logrado como parte de un esfuerzo colectivo y durante varias generaciones, según Arendt algunos judíos lo lograron en el período de lo que dura su propia vida y a fuerza de su propia imaginación personal. Así, para la filósofa alemana, será como individuos particulares que los judíos comenzaron a emanciparse de la tradición judía.

Y, como precisa Arendt, de este tipo específico de judíos surgió un notable grupo de "poetas, escritores y artistas judios" (Kohn \& Feldman editores, 2009, p.367) en quienes el alejarse de su tradición de origen, no los hizo degradar o decaer sino que por el contrario, dirá la filósofa alemana, los hizo ser sujetos creativos desde su acercamiento a la problemática judía. No obstante lo anterior, como señala Arendt (2005a), a pesar de que estos escritores, pensadores y 
artistas judíos tuviesen más de alguna cualidad en común, no encontraron recepción en una audiencia judía preparada y cultivada y no pudieron desarrollar una tradición específicamente judía en la literatura y en el pensamiento secular. En este sentido, Arendt (2005a) hará un llamado a la elaboración de "una cultura para los judíos" (p.20). Ello quiere decir que la filósofa alemana emplazará a la creación de una atmósfera cultural que cuide el "talento judio (...) que lleguemos a ser capaces de conservarlo dentro de nuestra propia comunidad" (p.20). Para lograr lo señalado, la pensadora propondrá un programa de reapropiación intelectual de la:

Gran tradición posbíblica religiosa y metafísica que tendremos que rescatar de mano de los teólogos y eruditos (con quienes tenemos, no obstante, una inmensa deuda de gratitud por haber preservado esa tradición). Pero habremos de descubrirla y ocuparnos nuevamente de ella a nuestro modo, en consideración a la gente para la que ya no constituye un pasado sagrado ni una herencia intocable (p.20).

En este sentido, para Arendt (2005a) será fundamental que la comunidad judía haga un espacio para aquellos judíos que entraron "en conflicto con la ortodoxia judía o que volvieron sus espaldas al judaísmo" (p.21), en diferentes momentos dentro de la historia judía. Ya que de acuerdo con la pensadora el talento creativo se ha dado con frecuencia entre estos sujetos y gracias a sus esfuerzos individuales a favor de la secularización, han ofreciendo los primeros modelos "para una amalgama de antiguas tradiciones con nuevos impulsos y sensibilidades sin los cuales una atmosfera específicamente judía es a duras penas concebible" (p.21).

Será en este contexto, que Arendt mencionará a los poetas, escritores y artistas judíos que se basaron en la figura del paria como arquetipo a utilizar en sus obras, como base y fuente 
de su inspiración y creatividad. Entre ellos se encontrarán, de acuerdo con la filósofa alemana, Salomón Maimón, Rahel Varnhagen, Heinrich Heine, Bernard Lazare, Shalom Aleijem, Franz Kafka y Charles Chaplin. (Kohn \& Feldman editores, 2009)

Sin embargo, indicará la pensadora, la influencia que estas figuras han tenido en el mundo no judío contrasta fuertemente con "el silenciamiento espiritual y político al que su propio pueblo ha condenado a estos grandes judios" (Kohn \& Feldman editores, 2009, p.367). Por ello, precisará la autora, todos ellos formarán parte de una "tradición oculta" (Kohn \& Feldman editores, 2009, p.367), al no ser reconocidos por la comunidad judía formal; serán "la única tradición de rebeldía consolidada" (Arendt, 2010a, p.141), basada no en el cultivo consciente de la continuidad del judaísmo, sino más bien en la persistencia y en la renovación del concepto del paria judío en la literatura y en la política, pero como una noción cada vez más ampliada.

En este mismo sentido, siguiendo los planteamientos de Arendt, Leibovici señalará que también se deben tomar en cuenta los proyectos filosóficos del siglo XX de pensadores que, de acuerdo con la autora, han tenido como preocupación el traducir lo que les importaba de la tradición judía en la cultura occidental. Entre ellos se encontrarán, como señala la filósofa francesa, Hermann Cohen, Franz Rosenzweig, Walter Benjamin y Emmanuel Levinas.

Ahora bien, para ampliar nuestro análisis acerca de la figura del paria consciente que conceptualizará Arendt, podemos recurrir nuevamente a la biografía particular de Rahel Varnhagen. En este sentido, Seyla Benhabib en su ensayo La paria y su sombra: sobre la invisibilidad de las mujeres en la filosofía política de Arendt, señalará que la actitud de Rahel hacia su judaísmo se caracterizará por un cambio de la psicología de la advenediza a 
la de paria consciente. Como planteábamos anteriormente, Rahel como parvenu negará su judeidad, borrando las diferencias que la constituyen. Sin embargo, Benhabib indicará que Rahel como paria consciente de sí misma, transformará la diferencia producida por su origen, considerada como fuente de debilidad y de marginalidad por la sociedad, por una fuente de fuerza y desafío. (Cruz compilador, 2006)

Y este cambio sucederá, como señala Arendt (2010c), debido a que Rahel adquirirá la capacidad de comprensión, aunque sea muy lentamente. Rahel comenzará a tomar consciencia de sí misma y a consolidar su facultad para entender y penetrar las cosas, su capacidad reflexiva y de tolerancia. Y ello lo logrará, de acuerdo con la pensadora, solo en su vejez y muy íntimamente, 
cuando convertida ya en una señora burguesa, consiga reconocer las conexiones entre las cosas, comprender lo que significaba para ella su condición judía, sus cualidades de paria y de marginada social.

\section{Momento conclusivo}

Como señala Arendt (2010a), en la creación de una historia social de los judíos en la vida europea del siglo XIX, fue decisivo que cada judío, de cada generación, tuviese que decidir individualmente si seguiría siendo un paria y continuaría excluido de la vida europea; o bien se convertiría en un advenedizo, intentando triunfar económicamente en el mundo gentil.

En este sentido, Arendt (2010a) precisará que cada individuo judío frente a su judeidad, frente a su condición y cualidad diferenciadora que le era dada; y ante su deseo de insertarse a la vida europea, sentirá al mismo tiempo el pesar del paria por permanecer fuera de la sociedad y no haber llegado a ser un advenedizo; y, simultáneamente, "la mala conciencia del advenedizo por haber traicionado a su pueblo y trocado la igualdad de derechos por los privilegios personales" (p.142).

Será en este contexto, que la filósofa alemana señalará que la mayoría de los judíos asimilados, denominados por la autora como judíos medios, se caracterizarán por su permanente falta de decisión para responder a su judeidad. Es decir, al estar frente aquello que les 'es dado' y al intentar insertarse a la vida prusiana, este tipo de judío no sabrá qué posición tomar frente a su condición judía.

Como plantea Arendt (2010a, p.143), en este período "la judeidad (...) ha sido tergiversada en cualidad psicológica”. En este sentido, Birulés explicará siguiendo los planteamientos de la filósofa alemana, que cuando la judeidad u otra diferencia es interpretada como una condición natural, como una enfermedad o como una cualidad psicológica, siendo este 
último atributo el que se vinculaba a los judíos del siglo XVIII y XIX en Alemania, esto dado podría impedir la participación en la esfera pública de los judíos, ya que todos sus actos se interpretarían como 
consecuencias necesarias de esta condición dada. (F. Birulés, entrevista personal, 13 de noviembre de 2012). En otras palabras, cuando para la sociedad prusiana, "los judíos se transformaron en un grupo social cuyos miembros compartían ciertos atributos y reacciones psicológicas" (Arendt, 2010a, p.141), el pueblo judío no podrá acceder al mundo común, ya que la condición de cada individuo será vista precisamente, por los miembros de la vida europea, como una característica psicológica del 'simple hecho de ser judío' y todos los actos que realicen los miembros de este pueblo, se interpretarán como consecuencia de su judeidad. Vinculándose así 'lo dado' a un tipo específico de conducta judía. (F. Birulés, entrevista personal, 13 de noviembre de 2012). Es por ello que Arendt (2005b, p.28) en la Conversación con Günter Gaus señalará que "si a una la atacan como judía, tiene que defenderse como judía". En este sentido, Birulés indicará que Arendt al decir estas palabras, no estará respondiendo a cómo se debe defender un judío frente a una situación hostil, sino que más bien lo que estará diciendo la filósofa alemana es que cuando se te ha expulsado de la esfera pública y no puedes participar de la comunidad política por tu ser dado, no se tiene más remedio que luchar desde ese sitio, desde tu condición otorgada. (F. Birulés, entrevista personal, 13 de noviembre de 2012). Esto quiere decir, como precisa Birulés, que cuando la sociedad interpreta lo otorgado judío como una condición psicológica, lo que está diciendo es que el judío por ser judío no puede actuar de otra forma, ya que tiene condiciones dadas que hacen que actúe igual que el resto de los miembros de su pueblo. Por lo tanto, agrega la pensadora, no se los hace responsables de sus acciones, sino que por el contrario, todas las acciones serán las consecuencias necesarias de su condición dada. Ya que cuando la condición judía se interpreta como una condición psicológica, cada individuo será considerado igual que todos los demás que tengan esta misma condición, sin apreciar las diferencias, cualidades, acciones y discursos que tiene cada sujeto como persona particular.

Birulés explicará así que lo dado tiene un presente en tanto lo hemos recibido y no hemos hecho nada sobre ello, pero a la vez se nos presenta al mismo tiempo interpretado. En este 
sentido, la filósofa española ejemplificará lo planteado indicando que no es lo mismo haber nacido en el Berlín de los siglos XVIII o XIX que en estos momentos en Nueva York. Como precisa la autora, en ambos casos se da algo dado pero se da presente, como una interpretación que viene a condicionar si lo dado judío es considerado "como una maravilla como ahora en Nueva York" (F.

Birulés, entrevista personal, 13 de noviembre de 2012) o si esto dado va a ser visto como una condición natural o como una característica psicológica como lo era para la sociedad prusiana. De esta forma, la filósofa española señalará que lo que Arendt estará planteando será que lo que permite la política es justamente singularizarse, poner en juego lo otorgado y representarlo. Es decir, como indica la pensadora, la política posibilitará el tomar la iniciativa sobre lo que ha sido dado y representarlo en la esfera pública, donde cada individuo lo representará de forma distinta a como lo representan los otros. Sin embargo, dirá la autora, cuando la judeidad es vista como una cualidad psicológica, esto dado impide a los individuos con dicha condición, a que puedan participar políticamente, ya que todos sus actos serán interpretados como consecuencias necesarias de su cualidad dada.

En este contexto explicará Arendt (2010a), que será justamente para la sociedad prusiana el considerar la condición judía como una cualidad psicológica, lo que los atraerá a vincularse con los judíos para poder saciar su "morboso apetito por lo exótico, por lo anormal y diferente como tal" (p.143). Por ello, los miembros de esta sociedad no promoverán que los judíos medios o asimilados resuelvan su modo de relacionarse con la vida europea, ya sea como advenedizos o como parias, ya que será precisamente esta ambigüedad en su situación, lo que hará que la relación con los judíos sea atractiva.

Sin embargo, como indica Arendt (2010a), para cumplir con las exigencias de la sociedad, a este tipo de judíos no les resultará fácil pretender no ser como judío pero seguir mostrando a la vez con suficiente claridad que eran judíos. Ya que lo que la sociedad les 
pedía a los judíos para asimilarse, era que se comportasen de un modo peculiar y distintivo y, al mismo tiempo, reconocible y estereotipado, es decir, un modo judío. No obstante lo anterior, de acuerdo con la pensadora, estos individuos solo podían mostrar un vacuo sentido de diferencia, el que era interpretado por la sociedad como si los judíos fuesen individuos extranjeros y, los extranjeros, de acuerdo con la autora, son el símbolo de la diferencia como tal y expresan aquellos ámbitos que el hombre no puede cambiar y en los que no puede actuar. 
Asimismo, los judíos medios serán considerados por la vida europea como sujetos que vivían en una alienación social, es decir, que habían perdido el sentimiento de la propia identidad o que vivían en un proceso mediante el cual transformaban su conciencia hasta hacerla contradictoria con lo que debía esperarse de su condición.

Así, como indica la filósofa alemana, durante generaciones este fue el modo de vida de la mayoría de los judíos asimilados, quienes a través de la concentración en una vida interior artificialmente complicada, intentaron dar una respuesta a las irrazonables y crecientes demandas de la sociedad prusiana. En este contexto, la pensadora señalará que el proceso por el que evolucionó la burguesía, a partir del debilitamiento de sus tradiciones y de sus recuerdos revolucionarios, se agregó el aburrimiento por la saturación económica y una indiferencia por todo aquello relacionado a la política. En esta atmósfera, como precisa Arendt (2010a, p.143) los judíos se transformaron en aquellas "personas con las que cabía distraerse por algún tiempo", ya que mientras menos iguales se los consideraba en relación a la sociedad mayoritaria, más atractivos resultaban, ya que los judíos representaban aquello que se salía de la norma, eran considerados en sí mismos como seres marginales y díscolos. Y, como indica la filósofa alemana, aquello fue precisamente lo que les abrió las puertas de la sociedad.

De esta manera, podemos observar, siguiendo los planteamientos de Arendt (2010a, p.128), cómo este tipo de relación logró "envenenar la atmósfera social", pervirtiendo las relaciones entre judíos y gentiles, lo que tuvo un efecto definido en la conducta judía en relación a su judeidad. Donde, de acuerdo con la filósofa alemana, la formación de un tipo específico de judío dependerá tanto de la discriminación que recibía, como asimismo de los privilegios especiales que le eran concedidos.

Ahora bien, si damos un siguiente paso y observamos los textos de Hannah Arendt analizados en este trabajo, podemos plantear cómo en estas obras se encuentra de forma transversal la pregunta acerca de lo que significa pertenecer al pueblo judío en la diáspora. Sin embargo, si bien la pensadora planteará interrogantes sobre la condición judía en la 
sociedad occidental, no nos dará 
una respuesta decisiva, sino que más bien nos abrirá nuevos cuestionamientos acerca de cuáles son las diferentes formas de responder a la judeidad.

En este contexto, si reflexionamos sobre lo que significa pertenecer al pueblo judío en la actualidad, podemos decir que el arquetipo del paria consciente, planteado por la filósofa alemana para definir a una minoría de judíos que se intentaba asimilar a la vida europea en el siglo XVIII y XIX desde su identidad cultural judía, se podría repensar como una de las formas posibles en las que el individuo judío podría pertenecer a su pueblo de origen de forma contemporánea.

¿Pero qué significará ser un paria consciente hoy? La figura del paria consciente en la actualidad se relacionará con el construir un tipo de identidad judía que es específica e individual. Se tratará de sujetos que se caracterizarán por querer liberarse a sí mismos como seres humanos particulares, es decir, como personas individuales, que desde su propio pensamiento autónomo y desde su libertad de consciencia, elegirán por su propia decisión el vincular su condición judía con su pueblo de origen. Ello quiere decir que estos individuos enfrentados con su judaísmo y su judeidad, no escogerán ser judíos por haber nacido de madre judía, tal como lo dice la tradición judía; por haber sido educados o formados en la religión, las costumbres, las creencias, el folklore o la historia de su pueblo; por haber crecido o vivido en un entorno judío; o por seguir un modelo impuesto desde sus propias comunidades o familias de origen. Por el contrario, estos sujetos enfrentados con aquello que 'les es dado' al nacer, elegirán por su propia iniciativa el aceptar su judeidad, utilizando para ello el pensamiento independiente (Selbstdenken) planteado por Lessing. De esta forma, el paria consciente aceptará su judeidad, como señala Birulés (Arendt, 2005a), ya que sentirá agradecimiento por su identidad judía y porque ello forme parte de su ser.

Por ello, la forma que tendrá para expresar su condición judía será a través de la originalidad en el pensar, la creatividad y la reflexión, generándose así un modelo concreto de judío vinculado a una identidad cultural secular, el que estará conformado por pensadores, artistas, poetas y escritores. Así, estos sujetos desde su condición judía, podrán 
generar obras creativas o de reflexión, tomando alguna iniciativa en relación al presente, al regalo que para ellos representará su judeidad.

¿Pero qué implicará el recibir este don contemporáneamente? Para el paria consciente de hoy la condición judía no será sinónimo de que aquello que le 'es dado' signifique vivir la existencia judía de forma estática y cerrada. Por el contrario, estos sujetos tendrán una actitud de empuje, de tomar decisiones, de poner en juego el regalo de la judeidad, es decir, tomarán la condición judía como algo que se puede modificar en función del pensamiento y del juzgar. Ello implicará que 'lo dado' estará en constante construcción, en cuestionamiento y reflexión, y no será algo concluido o determinado por el hecho de que sea otorgado al nacer. Para los parias conscientes el pensamiento judío no será una verdad que le pertenezca a un individuo cerrado en sí mismo. Para estos individuos, este pensamiento no tendrá relación con los resultados obtenidos, ya que los resultados significarían la solución final a los problemas que el pensamiento judío plantea para sí mismo. De esta manera, estos sujetos se caracterizarán, siguiendo a Leibovici (2005), por querer recoger en sus propias obras literarias o filosóficas contenidos relacionados al judaísmo, pero de una manera que escapa a la tradición religiosa o al control de las comunidades judías, ya que lo que les interesará será ingresar a la judeidad desde el 'pensar sin barandillas' planteado por Arendt (1995); desde la reflexión original sin restricciones.

El paria consciente por lo general no será un sujeto que active en la comunidad judía, ni tampoco en la sociedad receptora en la que habita. Lo que generará que su realidad sea conflictiva, que tenga que sufrir grandes costos culturales como individuo, conflictos y crisis de identidad. Incluso, muchas veces, será rechazado por su propia comunidad, 
quedando solo e incomprendido, ya que realizará obras literarias o filosóficas que no serán comprendidas o bien acogidas por los ambientes en los que se desenvuelve, siendo sus aportes culturales recuperados solo años después. El paría consciente presentará así un carácter desolado, al ser un individuo que no participa de su comunidad de origen, pero que a la vez, no tiene otra comunidad a la que poder llegar o pertenecer.

Sin embargo, la no pertenencia del paria consciente a su comunidad, no será porque esté en contra de la comunidad judía o porque se haya asimilado y se sienta ajeno a su herencia judaica. Sino que como señala Arendt (2008), tendrá esta actitud ya que para él "todas las tradiciones y culturas así como todo 'pertenecer' es igualmente cuestionable" (p.97). 
De esta forma, se tratará de pensadores y artistas judíos en los cuales los problemas y tensiones producidos por su identidad judía atravesarán sus obras, sin que por ello, éstas sean obras judías. Y, en muchos casos, aquellos intelectuales con una visión más amplia, desde sus propios problemas personales en relación a su judeidad, lograrán apreciar conflictos más generales y radicales, llegando a plantear el "cuestionamiento de la importancia de la tradición occidental como un todo" (Arendt, 2008, p.198).

Ahora bien, si uno de los requisitos de la vida judía es justamente vivenciarla en comunidad, ¿no sería un contrasentido que los parias conscientes experimenten su condición judía desde la individualidad? Para aproximarnos a una respuesta, podemos decir que los parias conscientes a través de sus palabras, de su andar, de sus obras y conductas, generarán ciertos 'disparos desde el desierto creativos y reflexivos', sin importarles necesariamente el impacto que éstos disparos filosóficos y literarios puedan generar en sus comunidades de origen o en la tradición religiosa establecida. Y sin preocuparles además, si formarán o no una tradición o una escuela tras de sí.

Sin embargo, podemos plantear que indirectamente, a pesar del carácter individualista de estas figuras, donde para ellos no es la pertenencia a la comunidad judía lo que estará en juego, su discurso y su actuar sí repercutirá en sus propias comunidades de origen. Es decir, los parias conscientes, desde su lenguaje y su acción ampliarán los límites de las comunidades judías, sin que quizás se lo propongan, siendo figuras que ayudan a la renovación y a la reinvención de lo judío. En este sentido, contar con personas que posean una función crítica y, por ello, viva dentro de una comunidad, permite que las mismas comunidades se conserven con un nivel de apertura y que no anquilosen su historia, cultura y religión como algo cerrado, limitado y extemporáneo.

Entonces, podemos plantear que en los parias conscientes habrá una construcción de sujetos críticos, no obstante que sus críticas y cuestionamientos no estén reflejadas en una sola voz o en una sola dirección, ya que lo que caracterizará a estos sujetos será su pensamiento individual sin que formen entre ellos una tradición específica. Por ello, su carácter crítico 
ante la problemática judía vendrá desde diferentes frentes o posiciones, sin que los parias conscientes se organicen y formen entre ellos un grupo particular. 
De esta forma, podemos observar que este carácter crítico del paria consciente estará ligado a su vez con la identidad política que tendrá esta figura. Ello quiere decir que en el paria consciente hay una búsqueda por recuperar un sentido político de lo judío en la diáspora, un aparecer político en la sociedad en la que habita. Así, este individuo tiene la necesidad de convertirse en una voz crítica pública para su comunidad judía de origen, a la cual enrostra, exige y demanda una participación política activa en el mundo común. Ya que el paria consciente buscará que públicamente aparezca la diversidad de posiciones que existen dentro del judaísmo, busca que la comunidad no sea algo cerrado en la ilusión de la esfera íntima, sino que justamente salga a la luz de la esfera común.

Esta actitud política del paria consciente también repercutirá en la sociedad receptora, en tanto que les muestra, a través de sus cuestionamientos y planteamientos, que la problemática judía, que el ser judío, no es algo monolítico. Así, el paria consciente a través de sus obras y su actuar viene a mostrar a la sociedad receptora gran parte de la cultura judía a quienes no son judíos; les muestra la pluralidad de visiones que existen en este pueblo y permite que personas de distintos orígenes puedan acercarse al judaísmo.

A su vez, podemos plantear que esta figura refleja que es posible conseguir desde la identidad judía una integración a la sociedad receptora que sea positiva, lo que cobra especial importancia si consideramos que la forma de asimilación de los judíos a la sociedad occidental, recorre gran parte de la temática de los textos de Arendt acerca del judaísmo y la judeidad.

Asimismo podemos decir, que este arquetipo vivirá en una situación intermedia, al interactuar política y críticamente entre ambas sociedades, la de origen y la de recepción, posibilitando que se produzcan oportunidades de intercambios culturales entre los distintos pueblos que componen el mundo común. Y justamente su identidad crítica y política, al actuar desde el borde u orilla de ambas culturas, será lo que le permitirá crear puentes entre ambas sociedades. 
¿Pero cómo se generarán estos puentes que unirán las orillas de las diferentes culturas? Para acercarnos a una respuesta podemos plantear que el pensamiento que propone el paria consciente 
no estará relacionado al silencioso diálogo platónico entre yo y yo mismo (Arendt, 2008), sino que su pensamiento se produciría en función de un diálogo tanto con los miembros de su propio pueblo de origen como con la sociedad mayoritaria. En este sentido, lo que tratará el paria consciente será de estimular a otros al pensamiento independiente, con tal de generar un discurso entre pensadores. Ya que en el discurso, la importancia política y su peculiar humanidad quedarán de manifiesto. Para el paria consciente será la conversación la que vinculará a los individuos entre sí en el mundo común, el que permanecerá inhumano hasta el momento en que los hombres y mujeres hablen de él.

De esta manera, el paria consciente, siguiendo la figura de Lessing, referida por Arendt (2008), no se sentirá obligado por la verdad, ya fuese impuesta por otros o por sus propios procesos de razonamiento, ya que se entusiasmará por el infinito número de opiniones que surgen cuando los seres humanos discuten sobre los asuntos del mundo común.

Así, estos sujetos, a través del discurso, del diálogo con los igualmente distintos, mostrarán que la asimilación también puede contener un valor positivo, en tanto que el discurso y la acción producen un intercambio continuo entre lo que significa la cultura judía y la cultura de la sociedad mayoritaria, posibilitando un crecimiento tanto de la comunidad judía como de la sociedad receptora, a través del enriquecimiento producido por el intercambio de ideas y posiciones distintas, que posibilitan una apertura de lo judío a la realidad.

De esta forma, los parias conscientes al realizar esta apertura a la realidad del mundo común, posibilitarán que lo judío aparezca en la esfera pública y que pueda ser visto y oído por todo el mundo, teniendo la más amplia publicidad posible. Ya que como indica Arendt (2010b), será en la vida pública donde la presencia de otros que ven lo que vemos y que oyen lo que escuchamos, asegurará la realidad del mundo y de nosotros mismos. Los parias conscientes hacen así que la identidad judía surja a la esfera pública, saliendo así de la oscura y cubierta existencia de la vida privada. 
El paria consciente al participar en la esfera pública a través del discurso y la acción, se insertará desde su propia identidad judía al mundo humano como "qua hombre" (Arendt, 2010b, p.200) y esta inserción será como un segundo nacimiento, en el que confirmará y asumirá el hecho de ser judío y su original apariencia. Este impulso surgirá del comienzo, que se adentró en el mundo cuando nacemos y al que respondemos comenzando algo nuevo bajo nuestra propia iniciativa. Y este comienzo no es el comienzo de algo, sino que es el comienzo de un alguien; de un alguien que es principiante por sí mismo.

De esta forma, el paria consciente viene a representar tanto para su comunidad de origen como para la sociedad receptora, lo nuevo, ante las certezas de las leyes y sus probabilidades; y, al ser capaz de la acción, se puede esperar de él lo inesperado, lo improbable. Por ello, la figura del paria consciente muestra que cada hombre es único y, por ello, que cada nacimiento implica que algo nuevo ingresa en el mundo, donde nadie estuvo allí antes que él por lo que nuevas reflexiones y pensamientos pueden aparecer y abrir espacios de libertad. (Arendt, 2010b)

Así, mediante la acción y el discurso, los parias conscientes buscarán la respuesta al “¿quién eres tú?” (Arendt, 2010b, p.202), descubrimiento que surge de las palabras y los actos entre la coexistencia de los igualmente distintos en la esfera pública. Ya que la cualidad reveladora del discurso y de la acción pasarán a un primer plano solo cuando las personas estén las unas con las otras en pura contigüidad entre sí. Y, aunque nadie sabe a quién se revela cuando se descubre a sí mismo, el paria consciente judío voluntariamente correrá el riesgo de la revelación, la que tiene su plena aparición en la esfera pública. 


\section{Bibliografía}

Arendt, H. (1995). De la historia a la acción. Barcelona: Paidós.

Arendt, H. (2003). Conferencias sobre la filosofía política de Kant. Barcelona: Paidós.

Arendt, H. (2005a). Una revisión de la historia judía y otros ensayos. Buenos Aires: Paidós.

Arendt, H. (2005b). Ensayos de comprensión 1930-1954. Madrid: Caparrós Editores.

Arendt, H. (2008). Hombres en tiempos de oscuridad (2 ${ }^{\mathrm{a}}$ Ed.). Barcelona: Gedisa.

Arendt, H. (2010a). Los orígenes del totalitarismo (4 ${ }^{\mathrm{a}}$ Ed.). Madrid: Alianza.

Arendt, H. (2010b). La condición humana (6ª Ed.). Buenos Aires: Paidós.

Arendt, H. (2010c). Rahel Varnhagen. Vida de una mujer judía. Barcelona: Lumen.

Calderón, P. (2013). Hannah Arendt y la condición judía: Paria y advenedizo, dos actitudes posibles frente a la judeidad. Tesis de magister. Universidad de Chile, Santiago, Chile. Cruz, M. (Comp.). (2006). El siglo de Hannah Arendt. Barcelona: Paidós.

F. Birulés, entrevista personal, 13 de noviembre de 2012, realizada en la Universidad de Chile, Facultad de Filosofía y Humanidades, Escuela de Postgrado.

Kohn, J. \& Feldman, R. (Ed.). (2009). Hannah Arendt. Escritos judíos. Madrid: Paidós. Leibovici, M. (2005). Hannah Arendt y la Tradición Judía. El Judaísmo a Prueba de la Secularización. México: Universidad Nacional Autónoma de 
México. Real Academia Española: www.rae.es

Weber, M. (1997). Sociología de la religión. Madrid: Istmo.

Weber, M. (1964). Historia económica general. México: Fondo de Cultura Económica. 